\title{
A Quantitative Analysis of Value-at-Risk based on Two-factor Pricing Model and GARCH Model
}

\author{
Qingqing Yu \\ University of California, Irvine, Irvine, CA 92697, USA
}

\begin{abstract}
Value-at-risk has become the main instrument for the measurement and management of financial risks. With innovative construction of multi-level capital market system and gradual improvement of functions of financial system in China, financial risks demonstrate some new uncertainties. With regard to quantitative analysis and the management of risks in Chinese financial market, adoption of some methods for quantification of value-at-risk is of greatly importance in the fields of both theory and practice. The constant improvement in research of theory and practice concerning financial development gives birth to all kinds of new instruments for measurement and management of financial risks, among which value-at-risk is a common new instrument applied in measurement and management of modern finance. In this paper, an empirical analysis is conducted on quantification of financial value-at-risk based on Two-factor pricing model and GARCH model.
\end{abstract}

Keywords: Financial Value-at-Risk; Two-factor Pricing Model; GARCH Model; Empirical Analysis.

\section{Introduction}

Financial risks management is an integrated systematic project which mainly consists the stages such as risks identification, risks measurement, management decision-making and implementation and risk control. Risks measurement plays the most critical role in financial risks management. Mainly relying on quantitative analysis, it measures the possibility, range and extent of losses caused by various risks, whereby providing reliable quantification basis for risks management. Value-at-risk is the main instrument for measurement of financial risks. Due to popularization of information technologies, highly innovative financial products, diversity and integration of world's financial markets, financial risks demonstrate multiple complicated evolutions and new uncertainties. Therefore, the measurement of financial risks should take into account some important influencing factors such as the linkage.

Since financial risks management is an integrated systematic project, its actual application involves many aspects and stages. Only complete macro control at all stages will safeguard more precise control of financial risks, maximum actual effect of financial management, reasonable prediction and prevention of various risks during financial development, avoid economic losses as far as possible, reduce the range and extent of losses and provide more accurate reference basis for construction quantitative model of financial value-at-risk and for empirical analysis.

\section{Construction of Two-factor Pricing Model and Empirical Analysis of Value- at-Risk}

\subsection{Construction of Two-factor Pricing Model}

The capital asset pricing model (CAPM) is an important theoretical basis of modern finance. In the study of financial risks, it has received great attention and reduced capital losses due to financial risks to some extent. However, constant improvement of financial theories and practice has given birth to many new instruments for measurement and management of financial risks, while the traditional capital asset pricing model (CAPM) cannot adapt to the rapid development in modern society. Therefore, the performance of capital asset pricing model (CAPM) has been questioned in the financial community. In recent years, experts of different nations have carried out in-depth analysis of capital asset pricing model (CAPM) and introduced the concept of value-at-risk into construction of capital asset pricing model (CAPM), stressing the important roles of factors such as 
risk premium, system risks, exchange rate risks and interest rate risks. Then, a Two-factor pricing model is constructed at wavelet multi-scale to strengthen quantitative analysis of financial value-atrisk. The capital asset pricing model (CAPM) can be expressed as: $\mathrm{E}($ ri-rf $)=\psi_{1} \operatorname{cov}($ ri, $\mathrm{r} \omega)+\psi_{2} \operatorname{cov}($ ri,s $)$.

Where, ri means rate of return on assets; rf means risk-free rate of return; rw means composite index-based rate of return at stock market; means rate of return concerning exchange rate; $\psi_{1}$ and $\psi_{2}$ mean the coefficient of comprehensive rate of return against the two risk factors. By introducing and integrating the risk factor of exchange rate into the capital asset pricing model (CAPM), a Two-

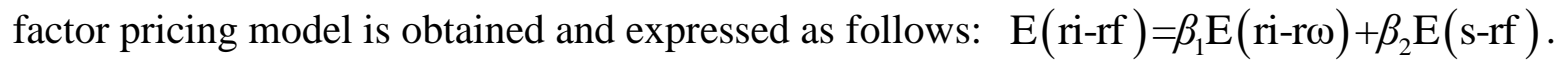

\subsection{Empirical Analysis of Quantification of Value-at-Risk}

Multi-resolution estimation is an important composition of Two-factor pricing model. It helps quantify the value-at-risk of investment portfolio at different time scales. Through analysis of the weigh of single assets investment, it reduces the error of Two-factor pricing model during use, lowers the risks in financial development, enables more accurate coping with uncertainties of market and maximizes and effective role of value-at-risk during financial development.

In this paper, the five stocks of China Unicom, Ping An Bank, Guizhou Maotai, Fuyao Glass and Kingsoft are studied. The statistical description is shown in Table 1.

Table 1. Analysis of statistical description

\begin{tabular}{|c|c|c|c|c|c|c|c|c|}
\hline $\begin{array}{c}\text { Stock } \\
\text { name }\end{array}$ & $\begin{array}{c}\text { Rate of } \\
\text { return }\end{array}$ & $\begin{array}{c}\text { Extremely } \\
\text { poor }\end{array}$ & Minimum & Maximum & Mean & $\begin{array}{c}\text { Standard } \\
\text { deviation }\end{array}$ & Skewness & Kurtosis \\
\hline $\begin{array}{c}\text { China } \\
\text { Unicom }\end{array}$ & r1 & 0.25 & -0.15 & 0.1 & 0.0016 & 0.0254 & 0.241 & 3.841 \\
\hline $\begin{array}{c}\text { Ping An } \\
\text { Bank }\end{array}$ & r2 & 0.51 & -0.37 & 0.14 & 0.0016 & 0.0295 & -2.316 & 3.267 \\
\hline $\begin{array}{c}\text { Guizhou } \\
\text { Maotai }\end{array}$ & r3 & 0.41 & -0.28 & 0.18 & 0.0024 & 0.0249 & -0.084 & 5.53 \\
\hline $\begin{array}{c}\text { Fuyao } \\
\text { Glass }\end{array}$ & $\mathrm{r} 4$ & 0.9 & -0.42 & 0.47 & 0.0009 & 0.0365 & 0.843 & 4.154 \\
\hline Kingsoft & $\mathrm{r} 5$ & 0.46 & -0.27 & 0.14 & 0.0002 & 0.0332 & -0.854 & 3.617 \\
\hline
\end{tabular}

In order to carry out more accurate empirical analysis of Two-factor pricing model, an in-depth analysis is conducted from both actual scale and wavelet scale to confirm the rate of return of assets successively. Then, a binary frequency range of band-pass filter was used to determine the sampling range. At the level-J scale, the corresponding time limit of actual investment is calculated with combination with daily closing data for in-depth study, thus determining that the optimal decomposition scale is 6 .

\section{The Study of GARCH Model and Empirical Analysis of Value-at-Risk}

\subsection{Analysis of GARCH Model}

Viewed from the micro structure of market, traders always place their own interest first, hoping to obtain maximum economic profit of enterprises with minimum capital costs. In the field of behavioral finance, an in-depth analysis is conducted on such behaviors of traders, where the characteristics of local fluctuations during traders' development are observed with combination with their various behaviors. On this basis, a GARCH model is established. As this model not only maintains the analysis function of but also expands the previous model, it is able to capture the influence of transaction information contained in different transaction periods to the fluctuation of rate of return on assets. 
In constructing GARCH model herein, the multi-period transaction behaviors of investors should be taken into account, so as to identify the mechanism of formation of asset price contained in multiperiod transaction behavior. The GARCH model is proposed from the perspective of wavelet multiscale analysis and further optimized and proved regarding reasonable regulation of relevant data. On the basis of composite index-based rate of return, the statistical characteristics are verified to further ensure the authenticity and reliability of GARCH model, providing basic guarantee for quantitative analysis of financial value-at-risk.

The expression of GARCH is:

$$
h_{t}=k+\sum_{i=1}^{q} G_{i} h_{t-i}+\sum_{i=1}^{p} A_{i} \in_{t-i}^{2}
$$

\subsection{Empirical Analysis of Quantification of Value-at-Risk}

Through quantitative analysis of financial value-at-risk with GARCH model, the important role of value-at-risk in financial development is further identified, followed by a summary of characteristics of corresponding statistical description and tests. The standard deviation of GARCH model will vary with changes of scale. The greater the scale, the greater the standard deviation. Namely, investors face varied investment risks within certain scope. In order to secure their own economic benefit, investors must develop a corresponding development strategy from different time scales. Furthermore, the skewness of statistical description at different scales also changes with the rate of return. Usually, the peak value of each scale is greater than three and demonstrates a positive correlation with scales. Within the sample period, the distribution of peaks of Shanghai Stock index-based rate of return varied significantly with changes of scales.

\section{Conclusion}

It can be learned from foregoing analysis that the development of financial industry in China at present stage should adapt to the times; and that a more optimal quantitative model should be constructed based on value-at-risk and a data modeling be conducted from wavelet analysis and GARCH, etc. In this paper, analysis is carried out mainly from the two orientations of Two-factor pricing model and GARCH model to further identify the important role of value-at-risk in financial management and development. Furthermore, as to the financial risks management instruments, the means of calculation are expanded, promoting steady improvement of financial development in China.

\section{References}

[1] WANG Xuan, CAI Junling, TANG Ling, HE Kaijia. VaR measurement for stock portfolio based on BEMD-Copula-GARCH model [J]. Systems Engineering --Theory \& Practice.2017, 37(2):303-310.

[2] RUBY P. KISHAN, TIMOTHY P. OPIEL A. Monetary Policy, Bank Lending, and the Risk-Pricing Channel[J]. Journal of Money, Credit and Banking. 2012 (4).

[3] LI Cuixia, CHEN Yuanyuan. The financial measurement of VaR under the GARCH model based on empirical distribution [J]. Acta Scientiarum Naturalium Universitatis Sunyatseni.2021, 60(4):177-182.

[4] Gui YufengLi Wei. Construction of Financial Risk Index based on Dynamic Factor Model[J]. Statistics and Decision.2017 (20):150-153. 